\section{Risk of developing eating disorders through the misperception of the body image and the adoption of bad eating habits in a sample of young volleyball athletes}

\author{
Ramona Fochesato, Sara Guidotti and Carlo Pruneti* \\ Department of Medicine and Surgery, Clinical Psychology, Clinical Psychophysiology and Clinical \\ Neuropsychology Labs, Polo Bio-Tecnologico, University of Parma, Via Volturno, 39, 43126 \\ Parma, Italy
}

\section{Abstract}

Objective: This preliminary study focused on the description of some dysfunctional perceptions of the body image and eating habits in a sample of young.

Methods: The results obtained by 55 amateur and professional volleyball players belonging to volleyball sports clubs located in the province of Reggio Emilia were examined. The age of the sample is in a range between 11 and 44 years. The participants completed the Pisa Survey for Eating Disorders (PSED), a questionnaire aimed at examining eating behavior and the perception of one's body image. The athletes' height and body weight were subsequently detected through direct measurement.

Conclusion: The data collected through the self-evaluation questionnaire and the measurements carried out by the study made it possible to analyze the perception of the body image and the eating habits of the volleyball players belonging to the sample and to compare them with the data in the literature. The data, albeit preliminary, allow us to confirm the existence of the discrepancy between the real body image and the desired one, in a group of young athletes, who favors the adoption of non-adaptive coping strategies to control one's own weight and body shapes typical of the vicious circle - strict diet, bingeing episodes, compensatory behaviors which characterizes eating disorders (ED). It is therefore considered essential that body image assessment is a practice implemented in the assessment routine of these athletes, especially in consideration of the fact that body image disturbance is a very common feature in this category and is one of the main risk factors of EDs.

\begin{abstract}
More Information
*Address for Correspondence: Carlo Pruneti, Professor, Department of Medicine and Surgery Clinical Psychology, Clinical Psychophysiology and Clinical Neuropsychology Labs, Polo BioTecnologico, University of Parma, Via Volturno, 39, 43126 Parma, Italy,

Email: carlo.pruneti@unipr.it
\end{abstract}

Submitted: Febraury 17, 2021

Approved: March 05, 2021

Published: March 08, 2021

How to cite this article: Fochesato R,

Guidotti S, Pruneti C. Risk of developing eating disorders through the misperception of the body image and the adoption of bad eating habits in a sample of young volleyball athletes. Arch Food Nutr Sci. 2021; 5: 007-017.

DOI: 10.29328/journal.afns.1001027

Copyright: @ 2021 Fochesato R, et al. This is an open access article distributed under the Creative Commons Attribution License, which permits unrestricted use, distribution, and reproduction in any medium, provided the original work is properly cited.

Keywords: Volley athletes; Body image; Eating habits; Eating disorder

(D) Check for updates

OPEN ACCESS

\section{Introduction}

The body image

The Body Image has been described as the mental representation of our body, the physical idea of our self [1]. Slade [2] further enriches the concept by defining the body image as "the image we have in our mind of the shape and the size of our body and the sensations we experience with respect to the individual parts of our body" or the subjective representation that every person has of it $[3,4]$.

Having a positive image of one's appearance is a sure contribution to the development of an adequate level of selfesteem [4-6].
The correlation between rejection of one's body image and dysfunctional eating behavior has already been well described in the literature as well as the socio-cultural factors (e.g. role of family, friends and media). These factors, together or not push adolescents to devise methods, or increase those already adopted, to modify their body [5,7-10].

In an epidemiological research on a sample of 1055 adolescent subjects, the clear tendency to physiologically abnormal eating behaviors and the high frequency of compensatory behaviors accompanied by considerable discomfort and a general non-acceptance of one's body emerged [11]. The transnational Health Behavior in School 
Aged Children study, carried out on 7 Veneto provinces, in 2000, examined the relationship between body image and eating disorders in a sample of nearly 4800 young people aged between 11 and 15 years. The discrepancy that emerged between objective (Body Mass Index or BMI) and subjective (questionnaire) indices suggests that young people from Veneto region (northern Italy) refer to a distorted body image. Satisfaction with their physical appearance was in fact quite low, in particular, while boys, who would like to see themselves more robust and masculine consider themselves too thin, girls whose has ideal of beauty is slender, consider themselves fat [12].

In a first study by Pruneti [13], on a sample of over 4000 adolescents from central-northern Italy, a high recurrence of both cognitive distortions and too rigid attitudes relating to the perception of the body self, as well as the presence of a frequent, often daily, dysfunctional eating behavior emerged. In particular, females denounce an attitude characterized by a more severe judgment towards their own body, a stronger desire to lose weight and greater determination in undertaking diets [4].

\section{Body image and eating disorders}

Nutrition and eating disorders, also referred as Eating Disorders (EDs), are characterized by a persistent eating disorder or diet-related behaviors that result in impaired consumption or absorption of foods that significantly impair physical health or psychosocial functioning [14]. The disorders of this nosological category are characterized by an excessive concern for weight and body size, to which selfesteem levels are strictly dependent; manifest themselves with a continuous control and a continuous measurement of the body. This phenomenon called < body checking > favors to further condition and maintain concerns about one's own body shape over time [15-17].

Anorexia nervosa and bulimia nervosa are the main EDs: both are characterized by the presence of an altered perception of body weight and self-image. These aspects favor the adoption of strict diets, mainly characterized by periods of fasting and exhausting sports activities, alternating with bouts of binging (the term "binge" refers to the ingestion of a significantly greater quantity of food than most individuals would take at the same time and in similar circumstances) and disorganized diet (snacks between meals without respecting schedules). These behaviors are experienced with negative emotions and feelings such as fear of gaining weight, self-loathing, sense of failure and guilt for not being able to maintain self-control, which in turn, however, can trigger further bulimic crises. Attempts are made to remedy this with what are called elimination conducts (self-induced vomiting, inappropriate use of laxatives, diuretics or enemas) $[4,14,16,18]$.

Along the ED continuum there would be, on the one hand, the restricted subtypes and, on the other, those characterized by binges. On the pole of excessive food intake there is the Binge Eating Disorder (BED), characterized by the presence of bulimic crises without resorting to compensatory and/or elimination behaviors for weight control [14].

These disorders are frequently associated with alteration in the way of seeing and living the body: with the term dysmorphophobia the DSM-5 refers to the more or less conscious concern for one or more defects or imperfections perceived in the physical appearance that are not observable, or only slightly, by others. The individual, in response to this concern that causes clinically significant discomfort, can carry out repetitive behaviors or mental actions that give rise to an obsessive search for change in body shapes [16,19].

Eating habits and eating disorders in the sport activity (competitive and not).

Many studies have found a close link between sports activity and the onset of EDs and agree that EDs are more common in female athletes than in non-athletes [20-28]. Lots of scientific papers address this complex issue. A research conducted including young athletes has highlighted the frequent tendency to perceive one's body in a distorted way: in fact, underestimating weight and overestimating height could be an indication of a denial/non-acceptance of the real appearance of one's body $[15,16]$. Some of these athlete report having suffered from problems related to their weight in the past (particularly between 6 and 18 years) and having followed hypocaloric diets motivated by the desire to lose weight and be more attractive [29]. Other studies have highlighted the association between perceiving being overweight and a tendency to perfectionism and social anxiety; moreover, those who overestimate their weight actually adopt a diet characterized by dysregulation $[21,27,30,31)$.

Many athletes undergo improper diets and unsuitable for sports often with the risk of finding themselves in a condition of undernutrition. In order to reduce body weight, they may resort to dysfunctional coping styles such as skipping meals, using rubberized clothing to sweat, vomiting, laxatives or diuretics [21,27,32]. A prolonged low-calorie diet that is not adequately monitored can induce an alteration in the relationship between the subject, the food and the perception of one's body and it is an important risk factor for a possible onset of EDs [22,29].

The risk of developing dysfunctional eating habits and EDs varies depending on the sport practiced and correlates with the increase in sporting level; in fact, elite athletes are more at risk [20-22].

Evaluation sports (gymnastics, diving, cheerleading, dance) require a lot of attention towards the appearance of the body. On the contrary, refereed sports (basketball, swimming, cycling) mainly emphasize training and physical conditions 
and, by not focusing attention on the aesthetic aspect of the body, are poorly associated with food problems [25,33].

Some sports emphasize thinness to improve performance and aesthetics, with a public display of the body. Therefore, weight is an important requirement and this can increase the risk of developing EDs [20, 23, 26, 34]. The elite athletes, who compete in sports focused on the thinness of the body, also report strong pressure from coaches, family and colleagues [35].

Parallel to the increase in ED, cases of "female athlete triad", a constellation of symptoms that includes the presence of menstrual dysfunction, insufficient availability of energy (with or without an ED) and decrease in bone mineral density appear to have increased $[32,34,36,37]$.

Several studies have examined the existing relationship between some social and interpersonal aspects, such as the relationship with friends, with the coach and with parents or the feeling accepted by friends, and the onset of EDs in types of sports characterized by a strong aesthetic component $[26,35]$.

This research has shown how the athletes perceive themselves with respect to their appearance but also to their physical ability. The perception of being physically able is more important than being physically attractive. Physical ability is the only one to be associated with both the quality of the relationship, with the coach and other athletes, and the presence of EDs [38].

Additional risk factors associated with the onset of ED are frequent weight fluctuations, sudden increase in training volume, traumatic events such as injury or change of coach [23].

In 2004, a study reported the prevalence of ED in athletes: the percentage would be $13.5 \%$, definitely higher than $4.5 \%$ of control subjects. In general, nutrition is used as a tool to improve not only physical appearance but also performance; in addition, the modification of food intake and assimilation would be frequent not only among athletes but also among technicians and coaches [39].

In a recent study [40], the authors administered some psychological tests to bikini, fitness, figure and bodybuilding athletes in order to detect any behavior suggestive for a diagnosis of ED. The author found that about half of the participants met the criteria for at least one ED (46.6\%); in particular, $27.3 \%$ showed clinically significant signs and symptoms while $19.3 \%$ could be considered as a subclinical condition. In addition, about half (48.9\%) of the participants reported having used dysfunctional behaviors to control their weight (bingeing episodes, self-induced vomiting and inappropriate use of laxatives) in the past three months. As described in other studies, the use of compensatory behaviors resulted in association with the desire to be thinner and dissatisfaction with one's appearance.
An early detection of alterations in eating behavior is important in order to prevent the development of ED such as Anorexia and Bulimia Nervosa [7,19,41]. In fact, early diagnosis is associated with early intervention, not only from a psychological but also medical point of view [42,43]. Indeed, high levels of physical activity in athletes with ED can cause numerous health problems: chronic fatigue, weakened immune system, longer healing times, anemia, electrolyte imbalance, endocrine abnormalities, amenorrhea and reduced bone density [36,37].

Therefore, the scientific literature emphasizes the need to prevent these problems by acting on the promotion, education and information aimed at young athletes and their instructors $[7,19,23,29,44-46]$.

\section{Current research}

Sample and method: A sample of 55 female athletes, aged between 11 and 34, belonging to volleyball sports clubs located in the province of Reggio Emilia (Cadelbosco Sopra, Gualtieri and Reggio Emilia), were included in the study. In particular, 17 girls belonging to the under12 (u12) category, registered with the Progetto Intesa Volley sports club, 11 under14 athletes (u14), 9 second division athletes (2d), 6 athletes belonging to the first division (1d) registered with the Bassa Reggiana Volley sports club, and 12 professional athletes belonging to the b2 (b2) team of the Polisportiva Gramsci were examined.

Each athlete carries out three weekly training sessions and participates in the sports championship at the Italian Volleyball Federation (Fipav) (Figure 1).

\section{Materials and methods}

In the first part of the study, the aim of the research was presented to the managers in charge of the sports clubs and the coaches of the teams. Once obtained the consent of the leaders, the study was illustrated to the teams and the meeting date agreed. The parents of the underage girls were informed in advance and expressed their written consent to participate in the study.

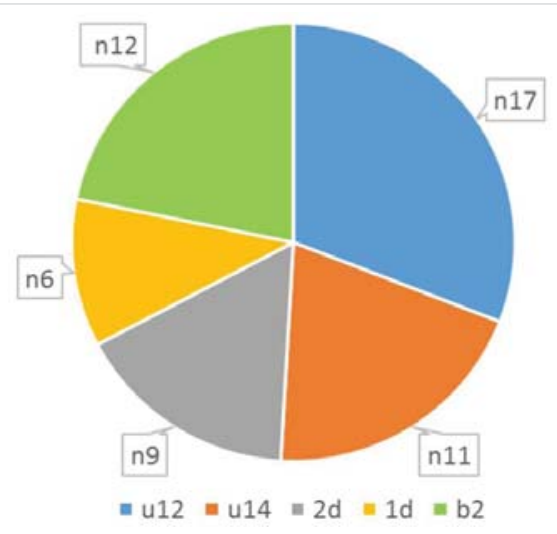

Figure 1: Sample of the study, team to which the athletes belong. 
Before training, the Pisa Survey for Eating Disorders questionnaire (PSED) [47] was delivered to the athletes and filled in individually. The PSED is a tool able to probing the behavioral and perceptual aspects relating to body image, as well as collecting information about eating habits, which can be more or less dysfunctional [47].

More precisely, the following areas are investigated by the questionnaire:

1. Interpersonal relationships (emotional relationship, sexual relationship, social contacts).

2. Body image (relationship with one's body, level of satisfaction, sectoral and global perception of it).

3. Dietary behavior (diet, binge eating, vomiting and use of laxatives).

4. Physical activity (type and frequency of activities carried out).

The PSED presents questions or requests posed in different forms:

- Statements to be confirmed or denied (Yes/No)

- Questions with two or more alternative answers

- Requests for attribution of a specific value corresponding to frequency, level of satisfaction, degree of intensity about certain situations proposed as an example

There is also an abbreviated version of the same questionnaire (PSED/A), more suitable for administration in pre-pubertal age (8-14 years).

The final part of the questionnaire includes two blank pages in which the subject is invited to freely write whatever he deems appropriate.

Investigating the perceptual and behavioral aspects with this tool allows to describe the image that the subject has of himself and all those dysfunctional strategies that are implemented to modify it. The athletes completed the self-evaluation questionnaire in order to detect the attitude towards their body, its size, the feelings aroused in its entirety or by some parts of it and eating habits.

Once the compilation was completed, the height of the athletes was measured (barefoot, making sure the support and alignment against the wall of heels, hips, shoulders and head) using a roll-up tape measure and a rigid book to facilitate the measurement.

Finally, the body weight of the athletes (with training clothing) was measured using a digital scale.

After carrying out at least two consecutive measurements, for both quantities, the data obtained from the arithmetic mean of the measurements was considered valid.

\section{Results}

The results refer to the analysis of the response frequencies to some items extracted from the entire questionnaire, concerning the areas of "body image" and "food habits", namely:

Item 1: "Academic level reached".

The athletes belonging to the youth teams under 12 and under 14 have reached a school level that reflects their age: 49\% elementary school, 6\% middle school (Figure 2). The adult athletes belonging to the second, $1 \mathrm{~d}$ teams and to the professional b2 series team have a high school diploma (31\% upper middle school) and a university degree (17\% degree). Most of the athletes with university degrees belong to the Serie B2 team (title achieved by $50 \%$ of the team).

Item 2: "Indicate your current weight in kg"

The data indicate an underestimation of the real body weight: $49.1 \%$ of the total sample indicates a lower weight. There is an underestimation of their weight on average equal to $1 \mathrm{~kg}$ in half of the athletes belonging to the u14 team (45.5\%), $2 \mathrm{~d}(55.6 \%)$ and $1 \mathrm{~d}(49.9 \%)$.

In the $\mathrm{u} 12$ team almost all the athletes show that they do not know the current body weight (82.4\% report a lower weight): the surveys and the comparison show, within the $\mathrm{u} 12$ team, an average underestimation of the weight of $3.5 \mathrm{~kg}$ (higher than the other teams). The b2 series team reported the complete correspondence between reported weight and measured weight.

$12.7 \%$ of the sample did not indicate the weight in the questionnaire and refused the measurement (Table 1).

Item 3: "Indicate your height in cm"

Most of the athletes belonging to the u12 (58.9\%), u14 (36.4\%), 2d (44.4\%) and 1d (50\%) teams indicate a height higher greater than the real one verified with the measurement (corresponding to $38.2 \%$ of the total sample). The team that

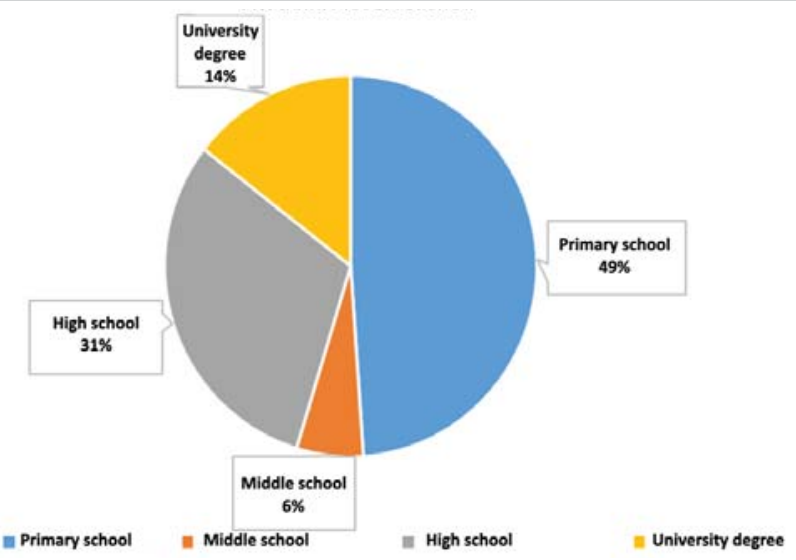

Figure 2: Item 1 "Academic level reached". 
most overestimated their height belongs to the $\mathrm{u} 12$ team (58.9\%), while $38.2 \%$ of the total sample correctly reported their current height.

The totality of the data concerning weight and height belonging to b2 team corresponds to the measurements carried out; the team is subject to periodic measurements by the coach.

Even with regard to height, a portion of the sample did not indicate their height in the questionnaire and did not make themselves available for the measurement (14.5\% of the total sample) (Table 2).

The aesthetic judgment on the body appearance expressed by the total sample is satisfactory (60\%), beautiful (24\%), ugly $(11 \%)$, very beautiful (5\%). No athlete considers her body bad (Figure 3 ).

Comparing the answers, teams of $\mathrm{b} 2, \mathrm{u} 12$ and $2 \mathrm{~d}$ show that they have a good consideration of their physical appearance.

The b2 team considers their body beautiful for $16.7 \%$. The u14 (27.3\%) and 1d (16.7\%) teams show dissatisfaction with their appearance indicating it is as ugly.

Table 1: Comparison between body weight reported (weight-r) by the athlete and measurement (weight-m).

\begin{tabular}{|c|c|c|c|c|c|c|}
\hline & \multicolumn{7}{|c|}{ Weight-r / weight-m } \\
\hline & $\mathbf{u 1 2}$ & $\mathbf{u 1 4}$ & $\mathbf{2 d}$ & $\mathbf{1 d}$ & b2 & Total \\
\hline Weight-r<weight-m & $82,3 \%$ & $5,4 \%$ & $55,6 \%$ & $49,9 \%$ & - & $49,1 \%$ \\
\hline Weight-r=weight-m & $5,9 \%$ & $7,3 \%$ & $33,3 \%$ & $16,7 \%$ & $100 \%$ & $36,4 \%$ \\
\hline Weight-r>weight-m & - & - & - & $16,7 \%$ & - & $1,8 \%$ \\
\hline Refusal of measurement & $11,8 \%$ & $7,3 \%$ & $11,1 \%$ & $16,7 \%$ & - & $12,7 \%$ \\
\hline
\end{tabular}

Table 2: Comparison between body height reported (height-r) by the athlete and measurement (height-m).

\begin{tabular}{|c|c|c|c|c|c|c|}
\hline & \multicolumn{7}{|c|}{ Height-r/height-m } \\
\hline Height-r<height-m & u12 & u14 & 2d & 1d & b2 & Total \\
\hline Height-r=height-m & $23,5 \%$ & $9 \%$ & - & - & - & $9,1 \%$ \\
\hline Height-r>height-m & - & $18,2 \%$ & $55,6 \%$ & $33,3 \%$ & $100 \%$ & $38,2 \%$ \\
\hline Refusal of measurement & $17,6 \%$ & $36,4 \%$ & $44,4 \%$ & $50 \%$ & - & $38,2 \%$ \\
\hline
\end{tabular}

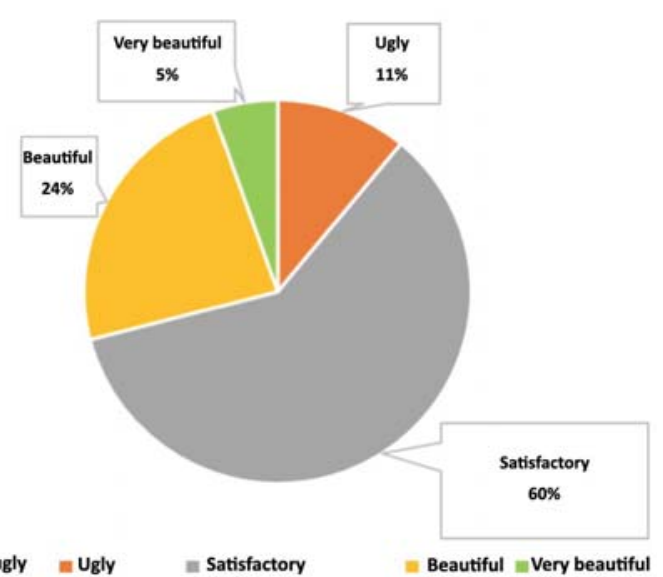

Figure 3: Item 13: "How do you consider your body from an aesthetic point of view?
Item 15: "Have you ever had weight problems?"

$29 \%$ of the total sample responds to having suffered from weight-related problems in the past (Figure 4).

Analyzing the answers divided by teams, it emerges that the $1 \mathrm{~d}$ athletes have had more weight problems in the past (50\%), followed by u14 (36.4\%), b2 (25\%), u12 (23.5\%) and $2 \mathrm{~d}(22.2 \%)$.

Item 16: "Have you ever felt too fat?"

$58 \%$ of the sample responded that they felt too fat (Figure 5). Regarding the situation within the teams it can be seen that the $1 \mathrm{~d}$ reports the highest percentage of positive answers to the question (83.3\%) followed by $2 \mathrm{~d}(66.7 \%)$, u12 (58.8\%), u14 (54.5\%). Team b2 reported the lowest percentage of positive responses (41.7\%).

Item 17: "Have you ever felt too thin?"

Most (91\%) of the athletes responded negatively while only $9 \%$ of the sample replied that they felt too thin (Figure 6), these answers belong to the youth teams of u12 (23.5\%) and u14 (9.1\%).

It's significant that the feeling of thinness is found in athletes aged between 10 and 13 years only.

Item 18: "How do you feel thinking about your body?"

The majority of the sample thinks about the body positively:

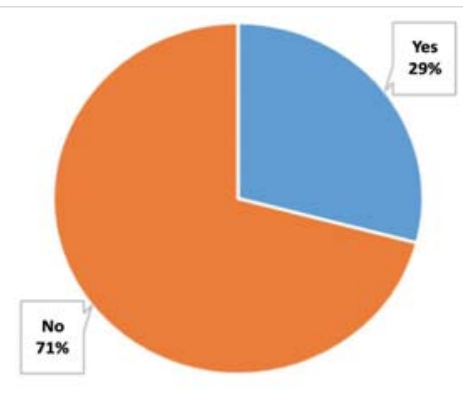

"Yes $=$ No

Figure 4: Item 15 "Have you ever had weight problems?" Total answers of the sample.

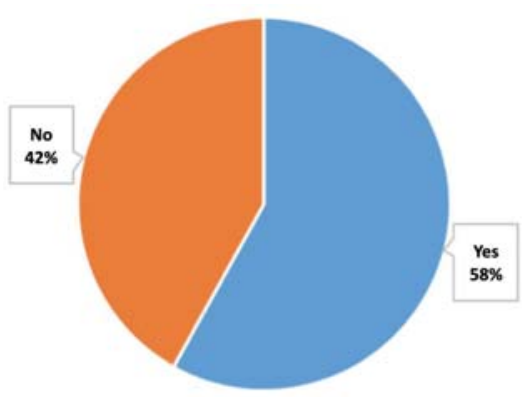

wes $=$ No

Figure 5: Item 16 "Have you ever felt too fat?" Total answers of the sample. 
$49 \%$ consider themselves satisfied, $13 \%$ very satisfied and $6 \%$ fulfill (Figure 7).

The $29 \%$ of the athletes are not satisfied and $4 \%$ of them think of their body with disgust. The athletes who have responded negatively to the question belong to the youth teams u12 and u14 (respectively 5.9\% and 9.1\% think with disgust about their body). $1 \mathrm{~d}$ is the team with the highest percentage of dissatisfaction (66.7\%). The teams that think about their body positively are $2 \mathrm{~d}$ and $\mathrm{b} 2$. The $66.7 \%$ of the latter team replied that they were moderately satisfied and $16.7 \%$ very fulfill.

Item 19: "What do you think about your weight?"

$45 \%$ of athletes thinks they should be thinner, $31 \%$ report feeling good about their weight, 18\% thinks they have to definitely lose weight, only $4 \%$ believe they should be a little fatter and only $2 \%$ believe to definitely gain weight (Figure 8 ).

Analyzing the answers divided by team, it emerges that $50 \%$ of the $1 \mathrm{~d}$ athletes respond that they must definitely lose weight and in general, about $40 \%$ of the athletes belonging to each team believe they should be a little thinner.
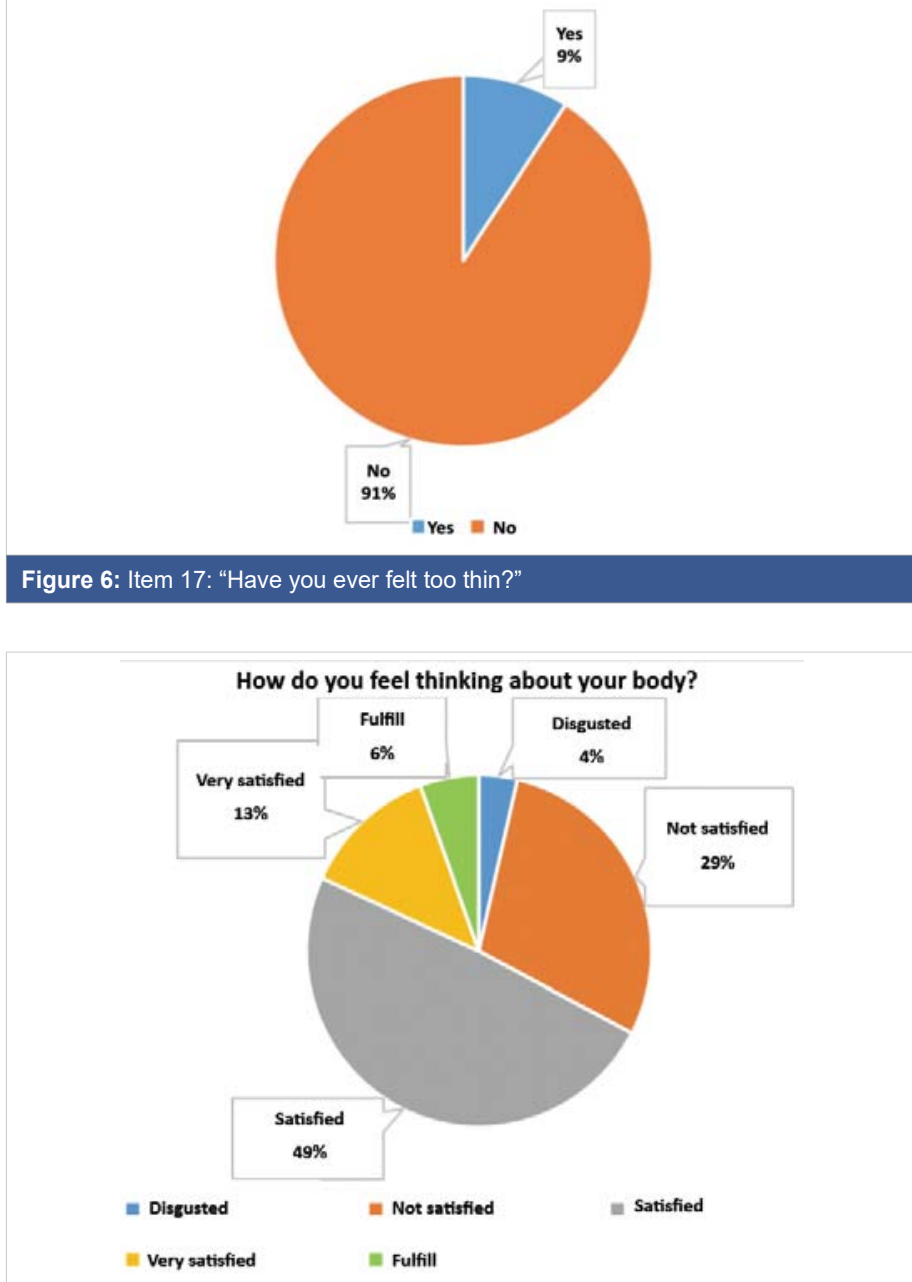

Figure 7: Item 18 "How do you feel thinking about your body?" Total answer of the sample.
$\mathrm{U} 12(41.2 \%)$ and b2 (41.7\%) athletes are the teams that consider their weight adequate.

At the item 21: «Have you ever been on a diet?» the $40 \%$ of female athletes have already embarked on a diet in the past and the $1 \mathrm{~d}(66.7 \%)$, the b2 (50\%) and u12 (41.2\%) have largely responded positively to the question (Figure 9).

\section{Item 22: "Are you on a particular diet now?"}

At this question, $13 \%$ of female athletes say they follow a diet also during the period of administration of the questionnaire (Figure 10). The athletes who responded positively to the question belong to the $\mathrm{u} 12$ (17.6\%), $1 \mathrm{~d}(16.7 \%), \mathrm{b} 2$ (16.7\%) and $2 \mathrm{~d}(11.1 \%)$ teams.

It is significant that the entire $\mathrm{u} 14$ team replied that they do not currently practice any type of diet.

The $16 \%$ of athletes report disordered eating behavior (Figure 11). The $2 \mathrm{~d}$ and the $1 \mathrm{~d}$ teams responded negatively to the question. Some athletes of the u14 (36.4\%), u12 (23.5\%) and b2 (8.3\%) teams believe they do not have correct eating habits.

Item 25: "Do you ever binge?"

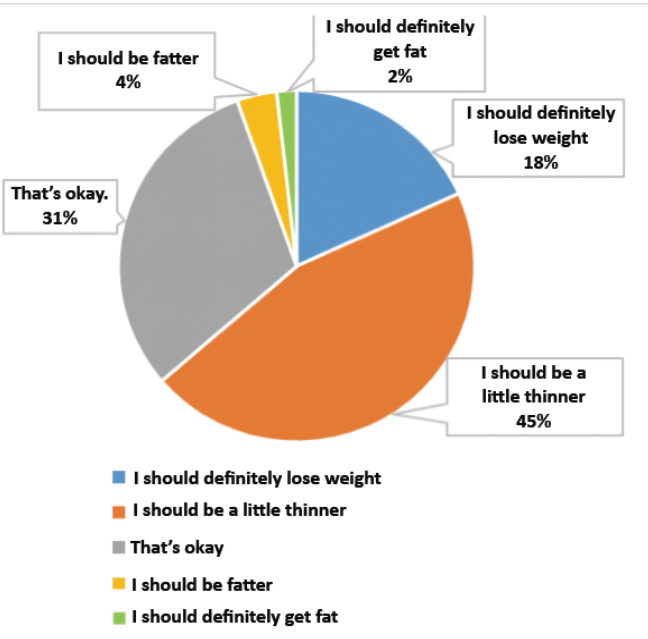

Figure 8: Item 19 "What do you think about your weight?" Total answer of the sample.

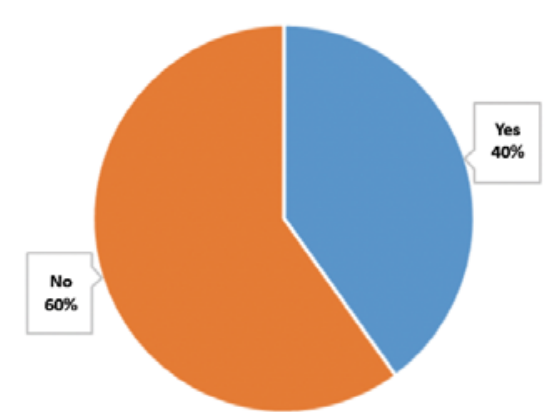

- Yes $=$ No

Figure 9: Item 21: "Have you ever been on a diet?". 
Binge eating appears to be a practice adopted by athletes albeit in a minimal percentage (13\% of the total sample), regardless of age. To the previous question, the $1 \mathrm{~d}$ athletes do not show that they eat in a disordered way, however they respond positively to this question (33.3\%). The practice of bingeing was also indicated by athletes in the b2 (16.7\%), $2 \mathrm{~d}$ (11.1\%), u14 (9.1\%) and u12 (5.9\%) series.

\section{Item 36: "Do you ever throw up?"}

The $98 \%$ of the athletes responded negatively. Vomiting does not appear to be a practice carried out by the sample examined. The athletes of $\mathrm{b} 2$ series appear to be the only ones to make use of this practice.

Different is the behavior adopted following the question proposed by item 39: "Do you use laxative substances?"

The majority of the sample (64\%) does not use laxatives but a significant percentage of female athletes indicate that they use them (34\%) (Figure 12).

\section{Discussion}

The search for food is a behavior aimed at satisfying

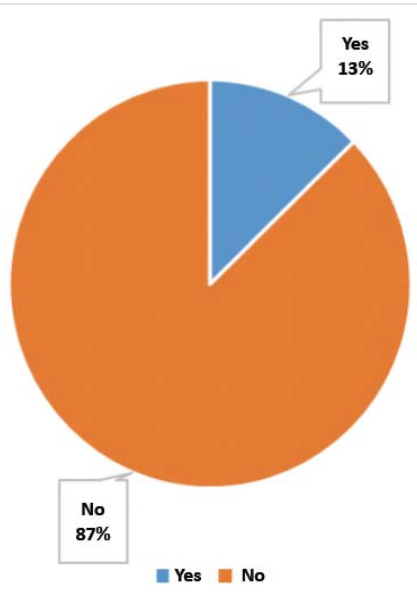

Figure 10: Item 22 "Are you on a particular diet now?" Total answers of the sample.

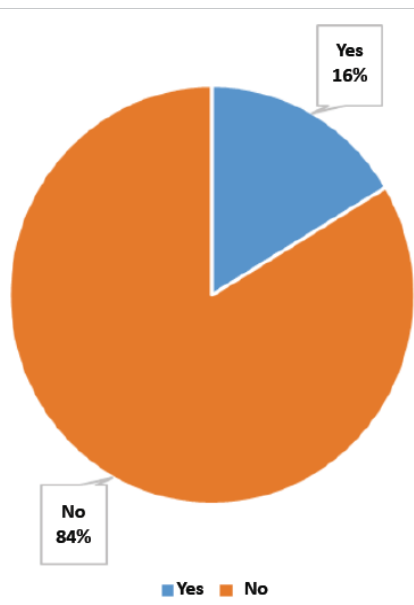

Figure 11: Item 24 "Do you think you eat in a disorderly manner?" Total answers of the sample.

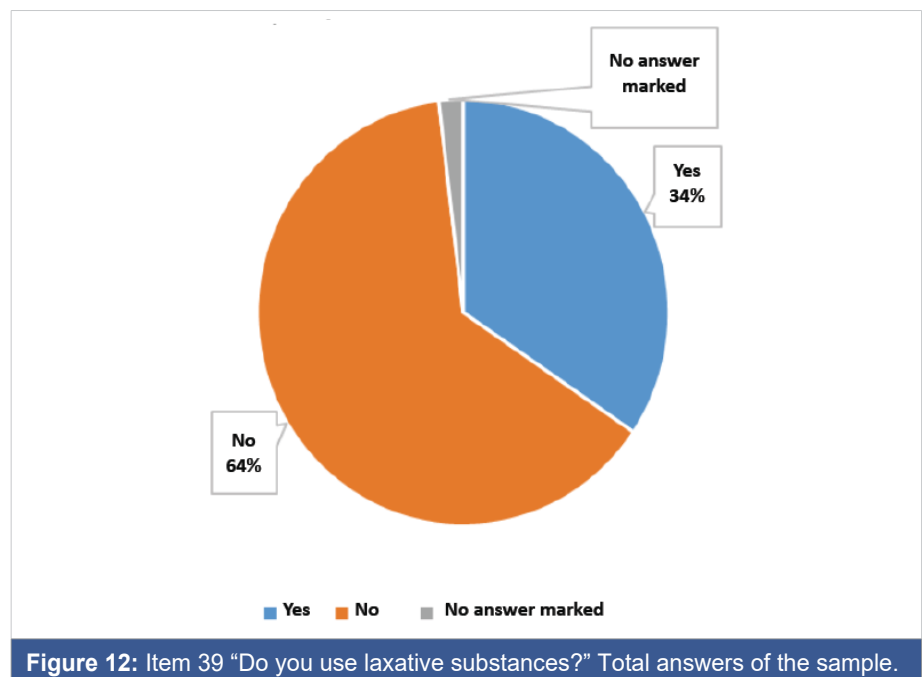

primary physiological needs necessary for the survival and conservation of the species. According to Maslow's pyramid model [48], organized hierarchically, the satisfaction of primary needs (physiological and safety) forms the basis for the construction of further needs, social needs (for love and belonging, for recognition and yield) which, once satisfied, leave room for even higher aspirations (needs of the Self, needs of transcendence).

It is well know that nutrition is also one of the behaviors regulated by neurophysiological mechanisms with negative feedback, to which the sensations of hunger and satiety correspond. Nevertheless more and more often, in more advanced societies and not necessarily similar to Western culture, the search for food is relatively independent of strictly biological needs but also influenced, triggered and maintained by a series of psychological factors such as lifestyle, habits, the presence of contextual, social and relational stimuli [4].

The images promoted by the media and the ideal of beauty validated by the current Western socio-cultural system could have a decisive negative influence even in this sample. The feelings of dissatisfaction related to the physical appearance affect body weight and the common perception is that of having to be thinner than the current status [49].

In the Western world, adolescents confront and compare themselves with the ideals of beauty proposed by cinema, television, internet and magazines. The images promoted by the media negatively affect above all girls, who, confronting the proposed models, do not perceive a correspondence with them, but feel inadequate, dissatisfied, overweight and approach restrictive diets and diets. The difference in the perception between the perceived silhouette and the desired silhouette has been defined as body image dissatisfaction (BID) $[3,49]$.

The pressure of the media towards thinness favors the development of a negative body image and consequently the adoption of unhealthy eating habits. 
Adolescence is a very vulnerable period for the development of ED [5,7-10,13,29,46]. It has been highlighted that it is common to find dissatisfaction with one's weight and body size in girls who attend the last grades of elementary school, as it happens for adolescents and young adults; moreover, especially girls, show lower levels of self-esteem in case of overweight $[11,13,39]$.

The comparison between weight and height data reported by the athletes and the objective measurements carried out shows how it is a common trend for all ages to indicate a lower weight and a greater height than the real body size. Therefore, the majority of the sample examined does not seem to have a correct perception of the characteristics of their body. Underestimation and overestimation of body weight and height, respectively, are present in both young adolescents in full body development and in adult athletes.

In the case of younger athletes, an unreal body image could be a consequence of the marked change and physical growth linked to puberty and adolescence, while the data reported by the adult athletes may suggest a lack of acceptance of the real dimensions of their body.

Professional players are the only athletes who show, with respect to height and weight, that they have a correct perception of their body regardless of whether it is a reason for dissatisfaction or contentment. However, elite athletes are subject to objective weight measurements by the coach on a monthly basis and this habit may have affected the data reported by the athletes in the questionnaire.

Although in a smaller percentage, a part of the sample did not respond to the items that required the indication of body measurements and did not undergo the measurement. This refusal could be linked to a possible lack of knowledge of one's own body, to a perception of the body image as negative and to the embarrassment in undergoing an objective measurement.

In addition, a third of the sample claims to have suffered from weight problems and have done a diet in the past. The concept of diet is thus associated with a low-calorie diet and adopted in order to lose weight. The data emerging from the study show an early approach to restrictive diets already from the adolescence.

Comparing the answers divided by team, the percentage of positive responses of the athletes in pre-pubertal age is very similar to that of the adult athletes. A similar outcome was repeated when it was investigated whether the participant was on a diet at the time of completing the questionnaire.

The results of this study confirm what has already emerged in the literature: many athletes undergo improper diets and unsuitable for sports: in order to reduce body weight, they may resort to dysfunctional coping styles [50-53]. The $40 \%$ of 11-12 years old, athletes indicate that they have followed a diet, and $17 \%$ of them state that they currently follow it. The younger athletes in fact report that they follow a diet, so to feel under food restriction but at the same time eating in a disordered way.

This precocity could be a consequence of the disordered and poorly balanced diet of the childhood and the beginning of the typical changes of puberty through which the body, previously a child, is transformed into an adult one. Therefore, the eating habits parents usually revise the children according to the period of growth, the metabolic changes of their daughter and adapted to a new relationship with the surrounding environment.

In fact, the team belonging to the u14 category, despite being dissatisfied from an aesthetic point of view, does not carry out any dietary diet; on the other hand, the adult athletes claim to have had weight problems and have been on diets in the past but not currently.

Therefore, the feeling of greater dissatisfaction from an aesthetic point of view belongs to adolescent athletes; youth and amateur teams show that they have a good consideration of their physical appearance; but professional athletes are the ones who have the best consideration.

In professional sport, at the beginning of the sporting season, the athlete participates in interviews and selection training sessions with the sporting club of his interest.

With increasing competitiveness, the selection of athletes focuses on sports career, motor talent and physical characteristics, which generally respect specific physical parameters for the practiced sport. Passing the selection and belonging to a standard sports team probably affects the athletes' self-esteem; an adequate level of self-esteem would therefore contribute to the development of a positive body image.

As competitiveness increases, compensatory and/or elimination behaviors for weight control, such as episodes of self-induced vomiting and use of laxatives, appear. The adult professional and semi-professional athletes are those who have claimed to use these methods, albeit in a minimal percentage. These methods could be used following sporadic episodes of binge eating because of restrictive and improperly balanced eating habits.

The data obtained from this survey, albeit preliminary, allow us to confirm the discrepancy between the real body image and the desired one in a group of athletes who, with the advancement of age and/or competitiveness, favors the adoption of certainly not adaptive strategies to control weight.

These findings accord with many studies present in literature that have found a link between sports activity and the onset of EDs [20-28]. 
Since early diagnosis of eating disorders is strongly associated with early intervention, it is important to detect cases at risk in order to prevent the development of ED such as Anorexia and Bulimia Nervosa $[7,19,41]$.

Therefore, these findings emphasizes the need to prevent these problems by acting on the prevention of ED promoting the education, the positive thinking and the information addressed to young athletes, their family and their instructors $[7,19,23,29,44,45,54]$.

\section{Conclusion}

This study investigated the possible presence of dysfunctional eating habits that can be considered risk factors for the development of EDs in a sample of volleyball athletes through body image assessment.

Investigating psychological and nutritional descriptive aspects, also by means of auxological and anthropometric indices (weight and height), made it possible to objectively ascertain the extent of cognitive distortions relating to the body self. The PSED questionnaire used in this study made it possible to know and analyze the behavior of the athletes. This tool was therefore useful for investigating and describing the dietary behavior of young athletes and how these are influenced by the perception of body image and the relative degree of satisfaction.

Some athletes report that they have suffered from weightrelated problems, to eat in a disorderly manner, to have followed, and still follow, hypocaloric diets and to make use of compensation and/or elimination methods to control weight.

The results of this study confirm the picture outlined by the current scientific literature: the athletes undergo dietary regimes that are incongruous and unsuitable for their sporting practice. Therefore, the need to detect and intervene on risk factors for psychopathologies emerges once again.

Although bodily dissatisfaction does not seem to be a universal characteristic of volleyball athletes, many are dissatisfied with their appearance and their purpose is to lose weight. Adolescence appears to be a very vulnerable period for the development of this type of disorder.

Elite athletes are also highly at risk; the risk of developing dysfunctional eating habits seems to increase with the progress of competitiveness and the sporting level.

On the sidelines of the evaluation carried out in this study, it is considered essential that the body image evaluation is a practice implemented in the routine evaluation of these athletes, especially in consideration of the fact that body image disorder is a very common feature in this category and is a major risk factor for EDs.

It is also considered necessary to promote the culture of nutrition in athletes, parents, coaches and sports managers.
Providing specific guidelines for the age of the athlete, for the type and the level of sporting activity can contribute to the creation of a correct relationship with food, to the improvement and the maintenance of sports performance by preventing the aggravation of dysfunctional eating habits in more serious disorders.

\section{Limitations and future line of research}

The presence of a small sample is a limitation of this study. Further studies should include more participants to create subgroups of female athletes, and possibly also male athletes, based on age in order to make comparisons between homogeneous groups.

The PSED tool has proved to be an excellent tool capable of detecting various psychological aspects related to dysfunctions in eating behavior. However future studies could include state tests and trait tests in order to analyze possible influences and interactions between eating behavior, mood and/or state symptoms and stable personality traits.

\section{Acknowledgment}

The research was conducted by Dr. Fochesato under the supervision and the support of the Parma University Clinical Psychology team, and part of this work was her Thesis dissertation.

\section{References}

1. Schidler P. Immagine di sé e schema corporeo. Milano: Franco Angeli. 1973.

2. Slade PD. Body image in anorexia nervosa. Br J Psychiatry Suppl. 1988; 153: 20-22.

PubMed: https://pubmed.ncbi.nlm.nih.gov/3072049/

3. Jiménez Flores $P$, Jiménez Cruz A, Bacardi Gascón M. [Body-image dissatisfaction in children and adolescents: a systematic review]. Nutr Hosp. 2017; 34: 479-489.

PubMed: https://pubmed.ncbi.nlm.nih.gov/28421808/

4. Pruneti C. Disturbi alimentari. Fisiologia e patologia del comportamento alimentare dal sovrappeso al sottopeso. Bologna: Società Editrice Esculapio. 2019.

5. Baceviciene M, Jankauskiene R. Associations between Body Appreciation and Disordered Eating in a Large Sample of Adolescents. Nutrients. 2020; 12: 752.

PubMed: https://pubmed.ncbi.nlm.nih.gov/32178334/

6. Gow ML, Tee MSY, Garnett SP, Baur LA, Aldwell K, et al. Pediatric obesity treatment, self-esteem, and body image: A systematic review with meta-analysis. Pediatr Obes. 2020; 15: e12600.

PubMed: https://pubmed.ncbi.nlm.nih.gov/32020780/

7. Fogelkvist M, Gustafsson SA, Kjellin L, Parling T. Acceptance and commitment therapy to reduce eating disorder symptoms and body image problems in patients with residual eating disorder symptoms: A randomized controlled trial. Body Image. 2020; 32: 155-166. PubMed: https://pubmed.ncbi.nlm.nih.gov/32000093/

8. Ohring R, Graber JA, Brooks-Gunn J. Girl's recurrent and concurrent body dissatisfaction: correlates and consequences over 8 years. Int $\mathrm{J}$ Eat Disord. 2020; 31: 404-415.

PubMed: https://pubmed.ncbi.nlm.nih.gov/11948645/

9. Jones JM, Bennet S, Olmsted MP, Lawson ML, Rodin G. Disordered 
eating attitudes and behaviors in teenaged girls: a study based of school. CMAJ. 2001; 165: 547-552.

PubMed: https://pubmed.ncbi.nlm.nih.gov/11563206/

10. Ricciardelli MA, McCabe MP. Dietary restraint and negative affect as mediators of body dissatisfaction and bulimic behaviour in adolescent girls and boys. Behav Res a Ther. 2001; 39: 1317-1328.

PubMed: https://pubmed.ncbi.nlm.nih.gov/11686266/

11. Pruneti CA, Di Nasso I, Ricotti L, Rossi S, Baracchini Muratorio G. Eating habits and self-perception in a sample of 1055 adolescents evaluated in the school setting. Minerva Pediatrica. 2002; 52: 529-530. PubMed: https://pubmed.ncbi.nlm.nih.gov/26920449/

12. Gava F, De Poli A. Rapporto sullo stato di salute e gli stili di vita dei giovani veneti in età scolare. Protocollo Internazionale Health Behaviour in Schoolaged Children dell'OMS Europa. 2021.

13. Pruneti C, Fontana F, Donalizio M, Buracchi G, Bicchieri L. Comportamento alimentare e immagine corporea. Studio epidemiologico su 4243 studenti italiani di scuole medie superiori e inferiori. Minerva Pediatrica. 2004; 56: 395-410.

14. American Psychiatric Association (APA). DSM-5. Manuale diagnostico e statistico dei disturbi mentali, tr. it. Milano: Raffaello Cortina Editore. 2014.

15. Nikodijevic A, Buck K, Fuller-Tyszkiewicz M, de Paoli T, Krug I. Body checking and body avoidance in eating disorders: Systematic review and meta-analysis. Eur Eat Disord Rev. 2018; 26: 159-185. PubMed: https://pubmed.ncbi.nlm.nih.gov/29528168/

16. Walker DC, White EK, Srinivasan VJ. A meta-analysis of the relationships between body checking, body image avoidance, body image dissatisfaction, mood, and disordered eating. Int J Eat Disord. 2018; 51: 745-770.

PubMed: https://pubmed.ncbi.nlm.nih.gov/29659039/

17. Shafran R, Lee M, Payne E, Fairburn CG. An experimental analysis of body checking. Behav Res Ther. 2007; 45: 113-121.

PubMed: https://pubmed.ncbi.nlm.nih.gov/16542638/

18. Pruneti C, Buracchi G. Multidisciplinary Approach to the Prevention and Treatment of Obesity; Psychol Psychother Res Stud. 2020; 3; 1-4.

19. Linardon J, Gleeson J, Yap K, Murphy K, Brennan L. Meta-analysis of the effects of third-wave behavioural interventions on disordered eating and body image concerns: implications for eating disorder prevention. Cogn Behav Ther. 2019;: 15-38.

PubMed: https://pubmed.ncbi.nlm.nih.gov/30307377/

20. Karrer $Y$, Halioua R, Mötteli S, Iff S, Seifritz E, et al. Disordered eating and eating disorders in male elite athletes: a scoping review. BMJ Open Sport Exerc Med. 2020; 6: e000801.

PubMed: https://pubmed.ncbi.nlm.nih.gov/33178441/

21. Surała O, Malczewska-Lenczowska J, Sadowska D, Grabowska I, Białecka-Dębek A. Traits of Orthorexia Nervosa and the Determinants of These Behaviors in Elite Athletes. Nutrients. 2020; 12: 2683. PubMed: https://pubmed.ncbi.nlm.nih.gov/32887460/

22. Kristjánsdóttir $H$, Sigurðardóttir $P$, Jónsdóttir $S$, Porsteinsdóttir $G$, Saavedra J. Body Image Concern and Eating Disorder Symptoms Among Elite Icelandic Athletes. Int J Environ Res Public Health. 2019; 16: 2728.

PubMed: https://pubmed.ncbi.nlm.nih.gov/31370175/

23. Sundgot-Borgen C, Bratland-Sanda S, Engen KME, Pettersen G, Friborg $\mathrm{O}$, et al. The Norwegian healthy body image programme: study protocol for a randomized controlled school-based intervention to promote positive body image and prevent disordered eating among Norwegian high school students. BMC Psychol. 2018; 6: 8.

PubMed: https://pubmed.ncbi.nlm.nih.gov/29510762/

24. Stewart TM, Pollard T, Hildebrandt T, Beyl R, Wesley N, et al. The Female Athlete Body (FAB) study: Rationale, design, and baseline characteristics. Contemp Clin Trials. 2017; 60: 63-71.

PubMed: https://www.ncbi.nlm.nih.gov/pmc/articles/PMC5546607/
25. Schwarz HC, Gairrett RL, Aruguete MS, Gold ES. Eating attitudes, body dissatisfaction, and perfectionism in female collage athletes. North Am J Psychol. 2005; 7: 345-352.

26. Toro J, Galilea B, Martinez-Mallen E, Salamero M, Capdevila L, et al. Eating disorders in spanish female athletes. Int J Sports Med. 2004; 26: 693-700.

PubMed: https://pubmed.ncbi.nlm.nih.gov/16158377/

27. Haase AM. Weight perception in female athletes: associations with disordered eating correlates and behavior. Eat Behav. 201; 12: 64-67. PubMed: https://pubmed.ncbi.nlm.nih.gov/21184976/

28. Byrne S, McLean N. Eating disorders in athletes: a review of the literature. J Sci Med Sports. 2001; 4: 145-159.

PubMed: https://pubmed.ncbi.nlm.nih.gov/11548914/

29. Pruneti C, Montecucco M, Fontana F, Fante C, Morese R, et al. Eating behaviour and body image in a sample of young athletes. Acta Biomedica. 2010; 81: 171-184.

PubMed: https://pubmed.ncbi.nlm.nih.gov/22530454/

30. Shu CY, Watson HJ, Anderson RA, Wade TD, Kane RT, et al. A randomized controlled trial of unguided internet cognitive behaviour therapy for perfectionism in adolescents: Impact on risk for eating disorders. Behav Res Ther. 2019; 120: 103429. PubMed: https://pubmed.ncbi.nlm.nih.gov/31279221/

31. Bruin AP, Oudejans RR, Bakker FC, Woertman L. Contextual body image and athletes disordered eating: the contribution of athletic body image to disordered eating in high performance women athletes. Eur Eat Disord Rev. 2011; 19: 201-215.

PubMed: https://pubmed.ncbi.nlm.nih.gov/21584913/

32. Nazem TG, Ackerman KE. The female athlete triad. Sports Health. 2012; 4: 302-311.

PubMed: https://pubmed.ncbi.nlm.nih.gov/23016101/

33. Petisco-Rodríguez C, Sánchez-Sánchez LC, Fernández-García R, Sánchez-Sánchez J, García-Montes JM. Disordered Eating Attitudes, Anxiety, Self-Esteem and Perfectionism in Young Athletes and NonAthletes. Int J Environ Res Public Health. 2020;17: 6754. PubMed: https://pubmed.ncbi.nlm.nih.gov/32948005/

34. Scheid JL, Stefanik ME. Drive for Thinness Predicts Musculoskeletal Injuries in Division II NCAA Female Athletes. J Funct Morphol Kinesiol. 2019; 4: 52.

PubMed: https://pubmed.ncbi.nlm.nih.gov/33467367/

35. Kong $P$, Harris LM. The sporting body: body image and eating disorder symptomatology among female athletes from leanness focused and nonleanness focused sports. J Psychol. 2015; 149: 141-160. PubMed: https://pubmed.ncbi.nlm.nih.gov/25511202/

36. Ackerman KE, Singhal V, Baskaran C, Slattery M, Campoverde Reyes KJ, et al. Oestrogen replacement improves bone mineral density in oligo-amenorrhoeic athletes: a randomised clinical trial. Br J Sports Med. 2019; 53: 229-236.

PubMed: https://pubmed.ncbi.nIm.nih.gov/30301734/

37. Papageorgiou M, Elliott-Sale KJ, Parsons A, Tang JCY, Greeves JP, etal. Effects of reduced energy availability on bone metabolism in women and men. Bone. 2017; 105: 191-199.

PubMed: https://pubmed.ncbi.nlm.nih.gov/28847532/

38. Scoffier S, Maïano C, Longueville FA. The effects of social relationships and acceptance on disturbed eating attitudes in elite adolescent female athletes: the mediating role of physical self-perceptions. Int $\mathrm{J}$ Eat Disord. 2010; 43: 65-71.

PubMed: https://pubmed.ncbi.nlm.nih.gov/19247995/

39. Milano W, Milano L, Capasso A. Eating Disorders in Athletes: From Risk Management to Therapy. Endocr Metab Immune Disord Drug Targets. 2020; 20: 2-14.

PubMed: https://pubmed.ncbi.nlm.nih.gov/31684854/

40. Whitehead J, Slater G, Wright H, Martin L, O' Connor H, Mitchell L. Disordered eating behaviors in female physique athletes. Eur $\mathrm{J}$ Sport 
Sci. 2020; 20: 1206-1214

PubMed: https://pubmed.ncbi.nIm.nih.gov/31771429/

41. Beals KA, Manore MM. Behavioral, psychological, and physical characteristics of female athletes with subclinical eating disorders. Int $\mathrm{J}$ Sport Nutr Exerc Metab. 2000; 10: 128-143.

PubMed: https://pubmed.ncbi.nlm.nih.gov/10861334/

42. Innocenti A, Franzoni F, Pruneti C. The role of nutrients in a dietary intervention in improving blood cholesterol profile and lowering cardiovascular risk. J Basic Appl Sci. 2014; 10: 96-101.

43. Innocenti A, Fusi J, Cammisuli DM, Franzoni F, Galetta F, et al. Effects of Mediterranean diet and weight loss on blood-lipid profile in overweight adults with hypercholesterolemia. Progress in Nutrition. 2019; 21: 4: 1-11.

44. Laramée C, Drapeau V, Valois P, Goulet C, Jacob R, et al. Evaluation of a Theory-Based Intervention Aimed at Reducing Intention to Use Restrictive Dietary Behaviors Among Adolescent Female Athletes. J Nutr Educ Behav. 2017; 49: 497-504.

PubMed: https://pubmed.ncbi.nlm.nih.gov/28601167/

45. Coelho GM, Gomes Al, Ribeiro BG, Soares Ede A. Prevention of eating disorders in female athletes. Open Access J Sports Med. 2014;
12: $105-113$

PubMed: https://www.ncbi.nlm.nih.gov/pmc/articles/PMC4026548/

46. Dufresne L, Bussières EL, Bédard A, Gingras N, Blanchette-Sarrasin A, et al. Personality traits in adolescents with eating disorder: A metaanalytic review. Int J Eat Disord. 2020; 53: 157-173.

PubMed: https://pubmed.ncbi.nlm.nih.gov/31633223/

47. Pruneti CA. Pisa Survey for Eating Disorders (forma A): Scala di Valutazione dei Disturbi del Comportamento Alimentare per l'età adolescenziale. Pisa: ETS. 1998.

48. Maslow AH. Motivation and Personality. New York: Harper \& Row. 1954.

49. Tiggemann M, Hayden S, Brown Z, Veldhuis J. The effect of Instagram "likes" on women's social comparison and body dissatisfaction. Body Image. 2018; 26: 90-97.

PubMed: https://pubmed.ncbi.nlm.nih.gov/30036748/

50. Johnson C, Powers PS, Dick R. Athletes and eating disorders: the national collegiate athletic association study. Int J Eat Disord. 1999; 26: 179-188.

PubMed: https://pubmed.ncbi.nlm.nih.gov/10422607/

51. Pruneti C. Positive Psychology, Old and new Theoretical Requirement for living this moment. J Depress Anxiety. 2016; 5: 1-5. 